\title{
Teoria dos Princípios e Ponderação em Robert Alexy: Posicionamentos na Doutrina Brasileira
}

\author{
Theory of Principles and Weighting in Robert Alexy: Placements in Brazilian \\ Doctrine
}

\begin{abstract}
RAFHAEL LEVINO DANTAS
Graduado em Direito (2007), Especialista em Direito Constitucional (2012) pela Universidade Federal do Rio Grande do Norte (UFRN). Atualmente, é Consultor da Consultoria-Geral do Estado do Rio Grande do Norte, Membro da Comissão de Estudos Constitucionais da Ordem dos Advogados do Brasil, Seccional do Rio Grande do Norte, e Mestrando em Direito Constitucional na Universidade Federal do Rio Grande do Norte (UFRN). Tem experiência na área de Direito, com ênfase em Direito Constitucional e Administrativo.
\end{abstract}

\section{DIOGO CALDAS LEONARDO DANTAS}

Bacharel em Direito pela Universidade Federal do Rio Grande do Norte, Especialista em Direito Constitucional pela Universidade Federal do Rio Grande do Norte, Mestrando em Direito Constitucional pela Universidade Federal do Rio Grande do Norte, Advogado.

Submissão: 28.02.2013

Decisão Editorial: 06.05.2013

RESUMO: 0 presente artigo tem o objetivo precípuo de apresentar as principais considerações críticas formuladas na doutrina jurídica brasileira em relação ao pensamento de Robert Alexy, tanto no que concerne à distinção entre princípios e regras, quanto no que diz respeito à técnica decisória da ponderação. Com o objetivo de enfocar as ideias de autores brasileiros que, sem desconhecerem a magnitude da contribuição de Alexy para o desenvolvimento da teoria principiológica e do método ponderativo, buscam empreender uma revisão tendente a melhor operacionalizá-los, 0 trabalho em exame se serve dos aportes de doutrinadores como Humberto Ávila, Leonardo Martins e Ana Paula de Barcellos, entre outros, propugnando, ao fim, por uma recepção adequada dos posicionamentos de Alexy na realidade pátria, de maneira a se evitar a concretização, sob o manto da ponderação, de uma aplicação subjetivista e sem legitimidade democrática das normas principiológicas.

PALAVRAS-CHAVE: Princípios; regras; ponderação; Alexy; posicionamentos; Brasil.

ABSTRACT: This paper has the main objective to present the main critical considerations in Brazilian legal doctrine in relation to the thought of Robert Alexy, both as regards the distinction between principles and rules, as with regard to operative technique of weighting. Aiming to focus on the ideas of Brazilian authors who, without being aware of the magnitude of the Alexy's contribution to the development of principles theory and the method of weighting, seek to undertake a review aimed at better operationalize them, the work in question uses the contributions of scholars like Humberto 
Ávila, Leonardo Martins and Ana Paula de Barcellos, among others, advocating, at the end, for proper reception of Alexy's placements in the national reality, in order to avoid, under the cloak of weighting, the implementation of a subjectivist application of standards without democratic legitimacy.

KEYWORDS: Principles; rules; weighting; Alexy; placements; Brazil.

SUMÁRIO: Introdução; 1 A teoria dos princípios de Robert Alexy e suas controvérsias; 1.1 A teoria dos princípios de Humberto Ávila; 1.20 entendimento de Virgílio Afonso da Silva; 1.30 entendimento de Leonardo Martins; 1.40 entendimento de Ana Paula de Barcellos; 2 A técnica da ponderação segundo Alexy e suas controvérsias; 2.1 A Ponderação Segundo Humberto Ávila; 2.2 A ponderação segundo Virgílio Afonso da Silva; 2.3 A ponderação segundo Luís Roberto Barroso; 2.40 entendimento de Leonardo Martins e Dimitri Dimoulis; Conclusão; Referências.

\section{INTRODUÇÃO}

Nas últimas décadas, a discussão acerca da teoria dos princípios e da técnica da ponderação constituiu, tanto no Brasil como no exterior, um dos temas mais candentes na esfera do Direito, estimulando o surgimento de uma plêiade de correntes doutrinárias e jurisprudenciais, todas elas desejosas de meIhor compreender o novo modelo de classificação das normas e de tomada de decisão diante de problemas jurídicos.

Egresso dos domínios da filosofia do Direito, o debate em foco acabou por produzir consequências significativas nos mais variados ramos jurídicos, trazendo, por exemplo, alterações profundas na forma como se raciocina e se põe em prática o Direito Constitucional da atualidade e, por via de consequência, reflexos impossíveis de serem ignorados no trato das questões cada vez mais intrincadas da sociedade complexa do presente.

Seccionada a realidade brasileira, vislumbra-se, sem maiores dificuldades, que as argumentações de maior envergadura a respeito do assunto gravitam em torno das concepções de Robert Alexy, destacado teórico contemporâneo da filosofia do Direito, cujos escritos, a despeito de uma certa recepção acrítica por parte de parcela da doutrina e da jurisprudência pátrias, também têm sido objeto de apontamentos críticos e sistemáticos na obra de respeitáveis autores nacionais.

Dada a extensa bibliografia existente entre nós limitada, em geral, à mera reprodução do pensamento de Robert Alexy, o presente artigo visa a discorrer sobre a visão de teóricos como - apenas a título de ilustração - Humberto Ávila e Leonardo Martins, cujas censuras aos pontos mais relevantes do arrazoado desenvolvido pelo filósofo e jurista alemão, longe de constituírem menosprezo àquele, consubstanciam importantes contribuições para o aprimoramento de sua operacionalização no dia a dia.

Assim, em um primeiro momento, voltado ao esclarecimento dos principais critérios diferenciadores das normas principiológicas e regulatórias, ex- 
plicitar-se-ão, de saída, os contornos essenciais da teoria de Robert Alexy, com especial destaque para aspectos como a dicotomia entre as estruturas, os modos de execução e, sobretudo, as formas de resolução de conflitos envolvendo princípios ou regras. Sequencialmente, explanar-se-ão as contestações de Humberto Ávila às formulações de Robert Alexy; a réplica de Virgílio Afonso da Silva em defesa deste e, por fim, as notas de Leonardo Martins e de Ana Paula de Barcellos acerca do tema.

Antes das observações conclusivas, e já ingressando no campo da ponderação, aludir-se-ão, igualmente, às percepções de Robert Alexy e, em seguida, de Humberto Ávila, Virgílio Afonso da Silva, Luís Roberto Barroso e Leonardo Martins, este em conjunto com Dimitri Dimoulis, sobressaindo-se altercações sobre tópicos, como a possibilidade de as regras serem ponderadas, a ausência de parâmetros objetivos no uso do método ponderativo e a inafastabilidade da subsunção no deslinde de todo e qualquer caso concreto.

\section{A TEORIA DOS PRINCÍPIOS DE ROBERT ALEXY E SUAS CONTROUÉRSIAS}

Entre as teorias dos princípios debatidas hoje, certamente a mais popular é a de Robert Alexy, o qual tomou como base parte do defendido pelo filósofo do Direito norte-americano Ronald Dworkin 1 . Assim, mostra-se imperativo, para um aprofundamento do tema, ainda que em medida estritamente necessária ao propósito do presente artigo, uma abordagem em conjunto das teorias de ambos os autores e o desenvolvimento de um paralelo entre a concepção de Dworkin e a de Alexy.

Pois bem, Dworkin, e também Alexy, classificam os princípios como uma modalidade de norma ${ }^{2}$ e os distingue das regras. Entretanto, vale frisar, os autores supracitados não são exatamente concordantes.

Dworkin distingue os princípios tanto das regras como das políticas. Nesta direção, o autor afirma usar o vocábulo em sentido estrito e assevera que princípio é "um padrão que deve ser observado, não porque vá promover ou assegurar uma situação econômica, política ou social considerada desejável, mas porque é uma exigência de justiça, equidade ou alguma dimensão da moralidade ${ }^{\prime \prime}$. Dentro desse contexto, os princípios possuem uma alta carga axiológica, refletindo um primado da justiça.

Já, em sentido amplo, Dworkin faz uma contraposição entre regras e princípios, afirmando que a diferença é de ordem lógica ${ }^{4}$. Desse quesito é que se aproveita a distinção de Alexy, a qual faz uma separação lógico-qualitativa, levando em consideração a estrutura das normas. Em suma, aqui, a distinção é

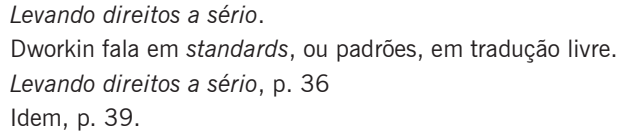


axiologicamente neutra ${ }^{5}$. Por conseguinte, pode haver tanto princípios fundamentais ao sistema como não, valendo o mesmo para as regras.

Essa diferenciação proposta por Dworkin e Alexy resulta em uma aplicação dos princípios que escapa do modelo da subsunção, necessitando-se de uma forma diversa. Isto se dá, principalmente, pela maneira distinta como funciona a execução de uma regra e de um princípio.

Inicialmente, Alexy parte da diferenciação consolidada na hermenêutica jurídica entre enunciado normativo e norma. O primeiro seria o texto do dispositivo legal, enquanto a segunda seria o que se extrai por intermédio da interpretação do primeiro. Dessa forma, sendo os princípios e as regras modalidades normativas, segundo o autor, a caracterização como uma dessas espécies dependeria do intérprete, fugindo da literalidade do texto de lei.

As regras, nas palavras de Dworkin, "são aplicáveis à maneira do tudo-ou-nada"6-7. Nesse sentido, a sua incidência não pode ser relativizada, devendo a consequência prevista ser aplicada quando a sua condição estiver presente. As controvérsias sobre a sua execução estão no âmbito da validade, demandando soluções que pressupõem a incidência dos critérios hermenêuticos da especialidade, temporalidade e hierarquia. Destarte, quando há um conflito entre regras (uma antinomia), Alexy afirma que, salvo na hipótese de uma cláusula de exceção, uma das regras deve ser declarada inválida e extirpada do sistema, uma vez que "o conceito de validade jurídica não é graduável. Ou uma norma jurídica é válida ou não é" ${ }^{\prime \prime}$.

Em contrapartida, os princípios funcionam de forma diferente. Dworkin garante que eles possuem uma dimensão que as regras não contêm: a do peso ou importância. Alexy também leva em consideração essa nova dimensão e assevera que os princípios têm um comportamento peculiar. Eles são "mandamentos de otimização" poderem ser satisfeitos em graus variados e pelo fato de que a medida devida de sua satisfação não depende somente das possibilidades fáticas, mas também das possibilidades jurídicas"10. Consequentemente, a aplicação dos princípios se sujeita não só aos outros princípios e regras conflitantes no caso em questão, como também às medidas adequadas e necessárias para a sua realização ${ }^{11}$.

Virgílio Afonso da Silva, Princípios e regras, p. 615.

Levando direitos a sério, p. 39.

No mesmo sentido, Robert Alexy (Teoria dos direitos fundamentais, p. 91) afirma que as regras "são normas que são sempre ou satisfeitas ou não satisfeitas. Se uma regra vale, então deve se fazer exatamente aquilo que ela exige; nem mais, nem menos. Regras contém, portanto, determinações no âmbito daquilo que é fática e juridicamente possível" [grifos do autor].

8 Teoria dos direitos fundamentais, p. 92

9 Aqui novamente Alexy afasta-se de Dworkin.

10 Teoria dos direitos fundamentais, p. 90

11 Virgílio Afonso da Silva, Direitos fundamentais, p. 46. 
Nesse passo, percebe-se que, enquanto as regras devem ser totalmente aplicadas sempre que ocorra o fato condicional para tanto, os princípios podem ser concretizados em graus distintos, segundo as peculiaridades do caso concreto.

Assim, diante dessas características diferentes, o conflito entre princípios dá-se na dimensão do peso dentro do fato, em que se atesta a precedência de um em face do outro e afasta-se a norma principiológica conflitante, sem, contudo, retirá-la do sistema. Para o desfecho de tal controvérsia, o aplicador do Direito efetua um "sopesamento" (ponderação) para atingir a solução adequada $^{12}$.

\subsection{A teoria doS PRINCíPIOS de HUMBERTo ÁvLLA}

Não obstante a influência da teoria dos princípios de Alexy na doutrina brasileira, delineada supra, Humberto Ávila parte, notadamente, da desconstrução da visão e dos critérios distintivos dos princípios adotados por Alexy e Dworkin para levantar novos elementos diferenciadores e caracterizadores das normas principiológicas.

Ávila inicia a sua argumentação criticando os métodos tradicionais de separação dos princípios e das regras. Em primeiro lugar, diz ele, há o critério do "modo final de aplicação"13, sustentado por Dworkin e Alexy e já exposto supra, onde as regras são aplicadas segundo o tudo ou nada e os princípios pela ponderação. Ávila afirma que o modo de aplicação da norma não está estipulado pelo enunciado normativo, mas é resultado da valoração feita pelo intérprete, o qual poderá levar a efeito uma execução distinta da inferida inicialmente. Aliás, o autor também ataca a diferenciação segundo esse elemento pelo fato de considerar que também as regras podem ser ponderadas, não existindo essa implementação absoluta uma vez presente a sua hipótese de incidência. Nessa vereda, o autor escreve que as regras podem deixar de ser aplicadas por razões substanciais concretas levadas em conta pelo aplicador ${ }^{14}$. Por conseguinte, o doutrinador reflete que a regra pode ser descumprida se a razão que a fundamenta entrar em conflito com outras razões, baseadas em outras normas. Igualmente, Ávila aduz que a presença de expressões vagas e abertas impossibilita a aplicação consoante o tudo ou nada. Logo, narra que "todas essas considerações demonstram que a afirmação de que as regras são aplicadas ao modo tudo ou nada só tem sentido quando todas as questões relacionadas à validade, ao sentido e à subsunção final dos fatos já estiverem superadas"15 [grifos do

2 Robert Alexy, Teoria dos direitos fundamentais, p. 93 a 99.

13 Ávila inicia a crítica pelo critério "hipotético-condicional", o qual não abordaremos, já que escapa ao propósito desse trabalho. Para um aprofundamento (cf. Humberto Ávila, Teoria dos princípios).

14 Em sua obra, Ávila (Teoria dos princípios, p. 49 e 50) expõe tal entendimento através da decisão proferida pelo Supremo Tribunal Federal no HC 73.662-9/MG, a qual será aprofundada no tópico 2.2.

15 Teoria dos princípios, p. 52. 
autor]. Para tanto, Ávila anuncia que isso é resultado do fato de que, para a sua construção como regra ou princípio, deve haver um processo prévio, e muitas vezes extremamente complexo, de interpretação.

Demais disso, o autor anota que os princípios distinguem-se das regras em razão da circunstância de estabelecerem um "estado de coisas"16, sem, contudo, determinar o comportamento devido para se atingir tal fim. Já as regras, ao contrário dos princípios, atuam como razão para o comportamento ${ }^{17}$, que é estabelecido por ela e que, independentemente dos seus efeitos, é considerado correto. Da mesma forma, Ávila esclarece que a aplicação segundo o tudo ou nada das regras não é precisa, pelo fato de haver situações onde as regras são aplicadas quando não se preenchem as suas condições (analogia), ou não são aplicadas quando implementada a sua hipótese fática ("cancelamento das condições justificadoras das regras por razões consideradas superiores pelo aplicador"18). Além disso, Ávila ${ }^{19}$ declara que a ideia de que as normas principiológicas podem ser aplicadas de forma gradual também é equivocada, já que essa noção de mais ou menos se refere à aproximação ao estado das coisas buscado pelos princípios, e não à sua aplicação.

Em segundo lugar, há o critério do "conflito normativo", o qual diferencia regras e princípios de acordo com a forma como se dá e é superada a colisão entre eles. Baseado, sobretudo, nos escritos de Dworkin e Alexy, esse parâmetro distingue as regras dos princípios pelo fato de que um conflito entre regras é solucionado por meio da declaração de invalidade de uma das normas conflitantes e de sua respectiva retirada do sistema. Já o conflito entre princípios aconteceria de forma particular, eis que, por terem a dimensão de peso, já exposta anteriormente, e serem mandamentos de otimização, o correspondente embate seria superado por meio da ponderação e da prevalência momentânea de uma norma sobre a outra. Ávila questiona esse critério de distinção, já que entende que as regras também são ponderáveis ${ }^{20}$, entrando em conflito concretamente (como os princípios) e não só abstratamente.

Além dessa defesa acerca da inviabilidade do uso da ponderação como traço a afastar regras e princípios, Ávila ${ }^{21}$ informa que a dimensão do peso não é exclusiva destes. O autor atesta que as regras também possuem essa qualidade, uma vez que, como já exposto, podem ser ponderadas. Aliás, o doutrinador vai além e certifica que, na verdade, a dimensão do peso não é característica dos princípios, mas, sim, das razões a que os princípios fazem referência, as quais são valoradas pelo intérprete.

16 Idem, p. 53

17 Os princípios são razões para o fim

18 Teoria dos princípios, p. 54

19 Idem, p. 56 e 57.

20 Aprofundaremos o estudo de críticas posteriormente, quando tratarmos da ponderação.

21 Teoria dos princípios, p. 65. 
Com base nessas críticas, Ávila põe em xeque a classificação dos princípios como mandamentos de otimização. Para tanto, expõe situações ${ }^{22}$ onde os princípios em jogo não são realizados na medida máxima. Por consectário, ensina que a marca distintiva entre as regras e os princípios não está no fato daquelas serem realizadas totalmente e estes na máxima medida, mas na "prescrição de conduta que resulta da sua interpretação" 23 . Portanto, registra o autor que os princípios somente estabelecem fins a serem perseguidos, cabendo ao aplicador determinar a conduta a ser usada para a sua concretização; as regras, de outra banda, já preveem o comportamento a ser executado, não possuindo o aplicador grande influência na sua realização.

Com fulcro em todas essas considerações, Ávila defende uma nova separação de espécies normativas em regras, princípios e postulados ${ }^{24}$. Além disso, afiança que o mesmo enunciado normativo pode ser interpretado das três formas, podendo-se inferir de uma proposição normas distintas.

Os dois primeiros podem ser distinguidos em conformidade com a natureza do comportamento prescrito, a natureza da justificativa exigida e a medida de contribuição para a decisão.

Nesse diapasão, segundo o primeiro critério, as regras são normas "imediatamente descritivas" 25 e "mediatamente finalísticas" 26 , as quais determinam de forma mais precisa a ação a ser efetivada e um dever de adotar-se o comportamento estabelecido, e, por isso, dependem menos da interpretação para a sua concretização. Já os princípios são normas "imediatamente finalísticas"27, que instituem um estado ideal das coisas a ser perseguido e um dever de adotar-se a medida necessária para tal realização.

No tocante ao critério da natureza da justificativa exigida, as regras distinguem-se pelo fato de demandarem uma menor justificação de aplicação. Por serem eminentemente descritivas e estabelecerem de forma mais precisa a conduta a ser concretizada, a sua execução não exige um grande ônus argumentativo, bastando, assim, a constatação da correspondência entre o acontecimento do plano fático com a previsão normativa e a razão que a fundamenta ${ }^{28}$. Já os

\footnotetext{
A ser aprofundado no tópico 1.2 .

Teoria dos princípios, p. 69.

4 Não aprofundaremos o estudo dos postulados aqui, já que não é pertinente para o trabalho. De qualquer forma, essa espécie de norma atua sobre a compreensão (postulados hermenêuticos) ou a aplicação (postulados de aplicação) de outras normas, sendo consideradas metanormas pelo autor. Portanto, tais normas são "diretrizes metódicas que se dirigem ao intérprete" e são consideradas "normas de segundo grau", enquanto os princípios e regras seriam "normas de primeiro grau" (Humberto Ávila, Teoria dos princípios, p. 142 a 144).

25 Humberto Ávila, Teoria dos princípios, p. 78

26 Idem, p. 79.

27 Idem, p. 78.

28 Quando há o acontecimento do fato que se adequa à previsão normativa, mas não com a razão que fundamenta a norma ou com outras razões, pode haver o descumprimento da regra, o que resulta em um ônus argumentativo maior. Essa questão será aprofundada posteriormente.
} 
princípios diferenciam-se em virtude de a justificação dever ser feita por intermédio da "avaliação dos efeitos da conduta havida como meio necessário para a promoção de um estado de coisas posto pela norma como ideal a ser atingido" 29 .

Quanto ao critério de medida de contribuição para a decisão, distinguem-se as regras pelo fato de possuírem uma "pretensão terminativa" ${ }^{30}$, em que buscam fornecer todos os aspectos relevantes para a formulação da sentença. Nessa esteira, Ávila as considera como "preliminarmente decisivas e abarcantes" ${ }^{\prime 11}$, tendo como objetivo uma solução específica. Já os princípios são considerados "primariamente complementares e parciais"32, haja vista que somente possuem parte dos elementos importantes para a decisão e não buscam produzir um resultado específico.

\subsection{0 entendimento de Virǵillo Afonso da Silua}

Doravante, faz-se necessário sublinhar o entendimento de Virgílio Afonso da Silva, o qual, diante das críticas de Ávila à teoria de Alexy, elabora um contraponto aos questionamentos suscitados pelo primeiro, travando um debate imprescindível para o aprofundamento do tema e a busca de esclarecimentos.

De início, o autor contradita a assertiva de Ávila, segundo a qual as regras também seriam ponderáveis ${ }^{33}$. Para tanto, concorda, preliminarmente, com as afirmações de Ávila de que a forma como a norma é aplicada não está determinada pelo enunciado normativo, bem como de que a distinção entre regras e princípios remete-se às modalidades de normas. Contudo, Silva pontua que, tendo por base a noção hoje elementar nos termos da qual norma é o que se extrai da literalidade do dispositivo legal (sua interpretação), a construção e aplicação das normas é algo ligado ao intérprete e não ao legislador e, consequentemente, ao enunciado normativo. Silva propugna isso, pois considera que, embora reconheça a diferença, Ávila parece confundir texto com norma.

De igual modo, Silva põe em dúvida a asserção de Ávila de que também as regras têm uma dimensão de peso, partindo dos exemplos fornecidos por este para desconstruir tal tese.

O primeiro exemplo diz respeito à hipótese em que um médico depara-se com uma situação onde dizer a verdade sobre a enfermidade do seu paciente, como impõe regra do Código de Ética Médica, pode piorar o seu quadro clínico devido aos abalos emocionais provocados pela má notícia. Nesse caso, Ávila

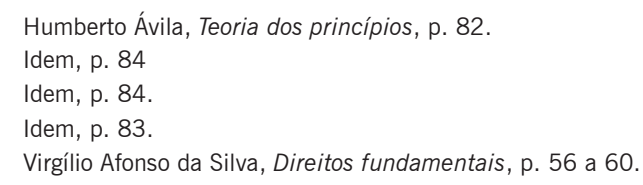


atesta que as duas regras em tela entram em conflito e que uma sucumbe em face da outra, sem, todavia, ser declarada inválida ${ }^{34}$. Silva indaga se as normas em apreço são realmente regras, sustentando que, na realidade, são princípios, pois impõem deveres prima facie. Por esse motivo, a ponderação dessas normas está correta e consentânea com a teoria de Alexy.

Já o segundo exemplo trazido por Ávila atine ao conflito da regra presente no art. $1^{\circ}$ da Lei $n^{\circ}$ 9.494/1999, a qual estabelece que o juiz está impedido de determinar, por medida liminar, o fornecimento de remédios pelo sistema de saúde a quem deles necessitar para viver, e a regra contida no art. $1^{\circ}$ da Lei no 9.908/1993 do Rio Grande do Sul, a qual obriga o Magistrado a impor o fornecimento de medicamentos pelo sistema de saúde a quem tiver precisão para sobreviver. De acordo com o autor, o conflito supera o abstrato, acontecendo concretamente e mantendo a validade das normas em questão. Ávila pontifica que a solução está no plano de aplicação, dependendo de uma ponderação entre as finalidades das regras colidentes ${ }^{35}$. Entretanto, novamente, Silva ${ }^{36}$ discorda da afirmativa de Ávila e proclama que o caso em perspectiva não é resultado de uma ponderação, mas da aplicação do postulado hermenêutico que estatui que a norma especial prevalece sobre a de caráter geral.

Igualmente, Silva vai de encontro à alegação de Ávila, de que os princípios não seriam mandamentos de otimização, já exposta anteriormente. Silva ${ }^{37}$ advoga que a proposta de Ávila de separar a colisão de princípios em quatro modalidades, de onde ele parte para desconstruir a estrutura dos princípios como mandamentos de otimização, é insubsistente. O primeiro caso trazido por Ávila diz respeito à hipótese onde a concretização dos fins instituídos por um princípio leva à realização dos objetivos introduzidos por outro. Aqui, Ávila ${ }^{38}$ salienta que não há de se falar em aplicação na máxima medida, mas em medida necessária para a implementação do outro princípio. No entanto, Silva ${ }^{39}$ frisa que não há conflito, já que o simples fato de um princípio concretizar outro não resulta em contradição. Além disso, o autor acredita que essa situação implica que um princípio exista em decorrência do segundo e que o primeiro seja um instrumento de realização do segundo, panorama que Ávila não expressa de forma elucidativa.

Já a segunda hipótese consiste no caso onde a realização de um princípio redunda na total inobservância do outro ${ }^{40}$. Ávila ressalta que nessa situação há uma aplicação dos princípios de forma similar à das regras, onde uma subjuga a outra totalmente, não havendo a sua incidência. Novamente, Silva responde a

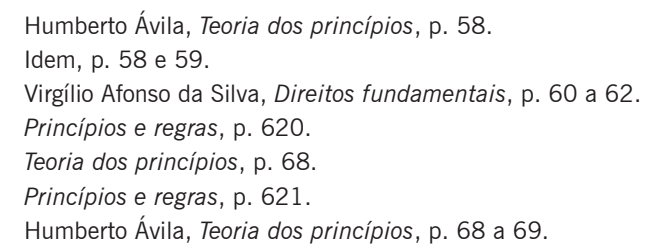


Ávila, esclarecendo que a concretização empreendida aqui não é a mesma das regras, uma vez que não há a declaração de invalidade de um dos princípios, retirando-o do ordenamento jurídico, mas somente o seu afastamento temporário. Nesse compasso, o conflito entre princípios, solucionado por meio da ponderação, a ser estudada posteriormente, gera uma decisão somente para o caso específico, podendo dar azo a outra solução em outro caso concreto.

Quanto à terceira ${ }^{41}$ e quarta hipóteses ${ }^{42}$ apresentadas por Ávila ${ }^{43}$, Silva conclui que não há conflito e, em vista disso, não avança na argumentação contra elas.

Silva também impugna a afirmação de Ávila de que os princípios devem ser aplicados na máxima medida, ou totalmente, assim como as regras. Silva considera que, como deveres prima facie ${ }^{44}$, a aplicação máxima dos princípios depende das possibilidades fáticas e jurídicas do caso, podendo ser restringida. Por conseguinte, o dever-ser estipulado abstratamente pelos princípios pode não ser o mesmo diante do caso concreto, já que é limitado fática e juridicamente.

\subsection{0 entendimento de Leonardo Marins}

Analisando o pensamento de Alexy sobre a distinção entre princípios e regras, Leonardo Martins, por sua vez, elenca três críticas fundamentais em seu desfavor, designando-as de (i) crítica epistemológica, (ii) crítica metodológica e (iii) crítica justeórica da autocontradição.

No que tange à crítica epistemológica, Martins parte da premissa segundo a qual "qualquer reconhecimento científico deve ser - para que possa ser reconhecido como tal - passível de ser refutado" 45 . De acordo com o autor, a teoria principiológica de Alexy, por ser revestida de uma amplitude excessiva, permite que toda e qualquer decisão da jurisprudência constitucional, por exemplo, possa ser apresentada como fruto de uma ponderação entre normas principiológicas em conflito. Nessa linha de raciocínio, registra Martins ${ }^{46}$ que:

[...] o potencial de revisão crítica de uma decisão judicial pela teoria principiológica é tão baixo, assim como também a refutabilidade de sua correção não está presente como em qualquer teoria científica. Portanto, a lei de colisão tem o condão de fundamentar qualquer ponderação e é imune à refutação [...], não preenchendo um pré-requisito básico de cientificidade.

41 A concretização do fim instituído por um princípio resulta na realização de parte do fim determinado pelo outro.

42 A concretização de um não resulta na aplicação do outro.

43 Teoria dos princípios, p. 69 e 70.

44 Qualidade que Ávila também reconhece (Humberto Ávila, Teoria dos princípios, p. 69).

45 Liberdade e estado constitucional, p. 76.

46 Idem, p. 80-81. 
No que pertine à crítica metodológica, Martins destaca que o conceito de regra trazido por Alexy possui um alcance muito limitado, configurando mesmo um retrocesso em relação ao modo como essa espécie normativa era definida antes do surgimento da sua teoria principiológica, especialmente porque o jurista alemão se circunscreve a "casos em que a argumentação jurídica é absolutamente prescindível, como naqueles casos de regras com conteúdo técnico e quantificador" ${ }^{\prime \prime 7}$. Ao ter em perspectiva exclusivamente algumas categorias de regras, Martins frisa que Alexy deixa de vislumbrar outras tantas cuja aplicação, a exemplo do que ocorre com os princípios, também demanda argumentação.

Sob o título de crítica justeórica de autocontradição, Leonardo Martins ressalta que, assim como as regras de exceção vocacionadas a dirimir antinomias - por exemplo, aquela que impõe a prevalência da norma superior sobre a inferior -, não "representam um tipo normativo específico, assim também o princípio de ponderação implícito na lei de colisão da teoria principiológica não tem estrutura diversa e, por isso, não representa um tipo normativo diferenciado" ${ }^{\prime 8}$. Com arrimo nesse pressuposto, Martins enxerga como regras o que a teoria principiológica de Alexy caracteriza como princípios - os mandamentos de otimização -, concluindo, portanto, pela improcedência, neste ponto específico, da distinção feita por aquele teórico entre os princípios e as regras.

Sem embargo das comentadas críticas epistemológica, metodológica e justeórica de autocontradição, Martins salienta que o advento da teoria principiológica de Alexy contribuiu fortemente para a expansão do fenômeno da constitucionalização do ordenamento jurídico, gerando tanto (i) mudança da relação entre os órgãos da jurisdição constitucional e o legislador, como (ii) preocupantes implicações teórico-constitucionais e teórico-democráticas.

No que respeita ao primeiro aspecto, segundo Martins, observa-se um incremento da atuação do Poder Judiciário - principalmente do órgão incumbido, de forma exclusiva ou prioritária, da apreciação de casos constitucionais em direção ao espectro tradicionalmente ocupado pelo Poder Legislativo, cujos membros, ao deixarem de ter a primazia no exame de importantes questões do debate público, acabam por abrir espaço para uma atividade jurisdicional que vai muito além da tarefa de controle das decisões legiferantes.

Outrossim, não se pode esquecer, continua Leonardo Martins, agora especificamente no que concerne às implicações teórico-constitucionais do fenômeno, que, "se se abandona a ideia de Constituição enquanto conjunto de parâmetros para o controle da atividade estatal [...], pode-se cair na armadilha de uma Constituição 'dirigente' ou [...] de caráter meramente programático"49,

47 Liberdade e estado constitucional, p. 81.

48 Idem, p. 82.

49 Idem,, p. 87. 
aniquilando-se, assim, uma das maiores conquistas do constitucionalismo nos últimos tempos: a da normatividade da lei fundamental.

Por último, quando versa sobre as consequências teórico-democráticas oriundas da constitucionalização do ordenamento jurídico, Martins assegura que, por um lado, "a não responsabilização do legislador por seus atos, causada pela perigosa ideia de que ele de qualquer forma sempre criará princípios a serem concretizados de acordo com todas as circunstâncias envolvidas no caso" ${ }^{\prime 50}$, reforça a hipertrofia do Poder Executivo em face do Parlamento.

Sob outro viés de argumentação, consoante sublinha oportunamente o autor, "com uma recepção acrítica da teoria principiológica, o legislador poderia contar com a atuação do Judiciário nos casos de suas omissões inconstitucionais ou com a leniência do mesmo Judiciário no caso de medidas excessivas consideradas 'razoáveis'" [do Poder Legislativo] de defender a ordem constitucional"52, como também "a espontânea observância das normas constitucionais que deveriam ser a regra do legítimo exercício dessa competência estatal"53.

\subsection{0 entendimento de Ana Paula de Barcellos}

Ao se deter sobre as principais distinções efetuadas pela literatura jurídica no que se refere aos princípios e às regras, de que são exemplos os aportes já trazidos à baila, Ana Paula de Barcellos consigna, em um primeiro momento, que a diferença estrutural entre ambas as espécies normativas pode ser mostrada, essencialmente, a partir de dois pontos de vista.

No primeiro deles, dissecado supra, Barcellos comenta, na esteira de Humberto Ávila, que "as regras descrevem comportamentos, sem se ocupar diretamente dos fins que as condutas descritas procuram realizar" ${ }^{\prime 54}$; já os princípios "estabelecem estados ideais, objetivos a serem alcançados, sem explicitarem necessariamente as ações que devem ser praticadas para que esse fim seja alcançado" ${ }^{\prime 5}$.

Numa segunda perspectiva, Barcellos indica que a separação de princípios e regras pelo fio condutor em exame (falta de semelhança entre as suas respectivas estruturas) pode ser descrita, também, de acordo com o critério dos efeitos que os tipos normativos regulatório e principiológico almejam gerar na realidade vivencial. Por corolário, "enquanto as regras são normas que estabe-

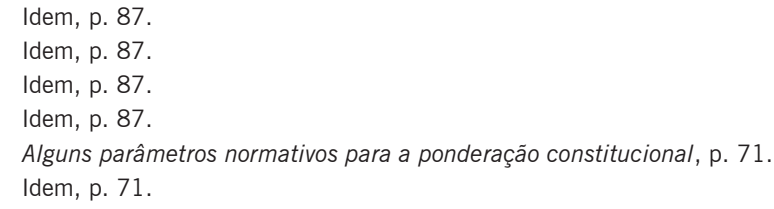


lecem desde logo os efeitos que pretendem produzir no mundo dos fatos" 56 , os princípios operam segundo outra lógica: uns "descrevem efeitos relativamente indeterminados" 57 , se distanciando, por isso, das regras, e outros, embora estatuam fins bem delimitados, tampouco se aproximam delas, pois "a identificação das condutas necessárias e exigíveis para a realização dos [seus] efeitos [...] não depende apenas da complexidade do próprio efeito e/ou da variedade de circunstâncias fáticas sobre os quais ele incide" 58 , somente se viabilizando quando entram em cena "distintas posições políticas, ideológicas e valorativas" 59.

N’outro giro, é dizer, para além do sobredito fator da diferença estrutural, Ana Paula de Barcellos dissocia princípios e regras também com fundamento no papel preponderante que desempenham dentro do sistema jurídico ou, mais precisamente, na contribuição prestada por tais espécies normativas aos dois grandes valores que, segundo ela, orientam todo e qualquer ordenamento: "De um lado, a segurança, a previsibilidade e a estabilidade das relações sociais e, de outro, a justiça" ${ }^{\prime \prime 0}$.

De um modo geral, Barcellos realça que, sobretudo ao se ter em mente as ordens inspiradas pela tradição romano-germânica, pode-se associar a aplicação de regras à busca por maior segurança jurídica, bem como a incidência de princípios ao que espacial e temporalmente venha a se entender por justiça, o que, de resto, se comunica diretamente com o próprio fato de que as regras, conforme assentado, tencionam dar existência a efeitos bem delineados, ao passo que os princípios geralmente não.

Por último, com a atenção voltada especificamente à seara constitucional, Ana Paula de Barcellos ressalva, ainda, uma distinção entre princípios e regras ligada ao contributo que oferecem às duas intenções principais de uma Constituição rígida e democrática, quais sejam, "estabelecer determinados consensos mínimos e colocá-los a salvo [...] das deliberações majoritárias e, de outro lado, preservar as condições para o desenvolvimento do pluralismo político" ${ }^{\prime 61}$.

Em termos simplificados, a autora exprime que as regras "respondem em geral pelas decisões associadas àquele consenso mínimo" 62 , já que, "através delas, o poder constituinte procura estabelecer desde logo condutas determinadas, específicas" ${ }^{\prime 63}$, se prestando as normas regulatórias, dessa forma, ao papel de concretizar o propósito da Constituição de ser o documento representativo dos

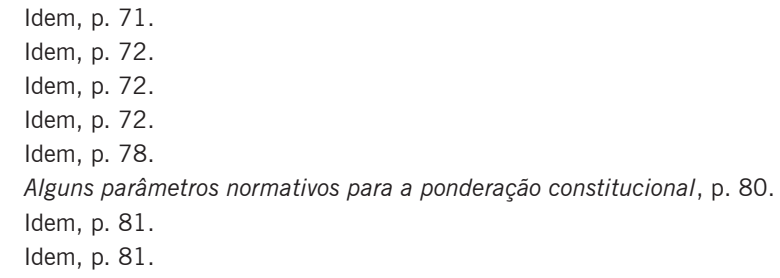


valores duradouros de uma determinada comunidade. Os princípios, por sua vez, colocam a autora, ao terem parte significativa de seu conteúdo edificada "pela deliberação majoritária, em função da convicção das maiorias em cada momento político" ${ }^{64}$, constituem os vetores principais de abertura do ordenamento constitucional ao espírito de cada época.

\section{A TÉCNICA DA PONDERAÇÃO SEGUNDO ALEXY E SUAS CONTROVÉRSIAS}

A ponderação, como exposto anteriormente, é o método proposto por Alexy ${ }^{65-66}$ para a solução do conflito entre princípios - e esse seria um dos critérios diferenciadores das regras. Fundada na "lei de colisão", a antinomia entre princípios seria resolvida por meio da constatação de qual norma possui precedência no caso concreto. Segundo o autor, busca-se "definir qual desses interesses - que abstratamente estão no mesmo nível - tem maior peso no caso concreto" $\left[\right.$ grifos do autor ${ }^{67}$.

Diante disso, deve-se fazer um sopesamento (= ponderação) dos valores envolvidos na problemática em questão para se chegar à decisão mais consentânea com o Direito.

Para tanto, Alexy defende a aplicação do que ele chama de "lei de colisão", que seria um mecanismo de solução do conflito de princípios. Isto é resultado do comportamento dos princípios em confronto, hipótese em que um não deve ser declarado inválido e retirado do sistema, mas somente estabelecida uma solução de precedência condicionada, tendo em vista as circunstâncias presentes no caso concreto ${ }^{68}$.

A precedência é condicionada pelo fato de que somente existe diante de certas condições, não havendo, em abstrato, um peso maior de um princípio em relação a outro. A precedência incondicionada só existe quando se considera que um interesse em conflito com outro sempre terá maior peso, sendo, por isso, considerado "superior", independentemente do caso concreto ${ }^{69}$. Dessa indeterminação da precedência em abstrato entre os princípios é que parte a ponderação para tentar solucionar o caso concreto.

Portanto, somente nas hipóteses em que há uma situação na qual, em abstrato, não se atribui um valor maior a determinado princípio, é que cabe o uso da ponderação, devendo o resultado só valer para o caso concreto sob exame $^{70}$.

64 Idem, p. 81.

65 Teoria dos direitos fundamentais, p. 94.

66 Para uma análise interessante da ponderação segundo Alexy (cf. Frederick Schauer, Balancing, subsumption and the constraining role of legal text).

67 Teoria dos direitos fundamentais, p. 95.

68 Idem, p. 96.

69 Para um aprofundamento, Robert Alexy, Teoria dos direitos fundamentais, p. 97.

70 Observaciones sobre las antinomias y el criterio de ponderación, p. 105. 
Igualmente, deve-se destacar que a solução dada pelo magistrado a determinada situação não impõe uma precedência a ser seguida sempre e em todas as hipóteses de conflito. O resultado da ponderação somente vale para casos iguais, não se configurando uma precedência absoluta, ou a priori, de determinado princípio sobre outro. Nas palavras de Prieto Sanchis, estabelece-se uma "hierarquia móvel"71, vez que não se exclui uma solução diferente para os demais casos.

A ponderação analisa as razões das normas conflitantes no caso apresentado. Busca-se, então, averiguar se há razões suficientes para que determinado princípio tenha prioridade sobre a outra norma protegida e colidente. Segundo Alexy, o resultado da ponderação dos interesses em disputa é uma regra "que, diante da presença da condição de precedência, prescreve a consequência jurídica do princípio prevalente $\mathrm{e}^{\prime \prime 2}$. Assim, as condições que determinam a prioridade de determinado princípio são as hipóteses fáticas de aplicação da regra, a qual é resultado da ponderação.

\subsection{A ponoeração segunoo Humberto ÁviLa}

Como já exposto supra, Ávila busca demonstrar, a partir de uma crítica à teoria de Alexy, que a ponderação como critério de distinção entre as regras e os princípios é equivocada, já que também as regras seriam ponderáveis.

Para tanto, refuta a ideia de que somente os princípios entram em choque no plano concreto, onde seria aplicada a ponderação ${ }^{73}$. Na mesma medida, assevera que as regras também entram em conflito nesse plano, situação em que se dá a ponderação entre elas, e que a solução ocorre atribuindo-se maior peso a uma das tais, sem, contudo, declarar a outra inválida, mantendo-se ambas dentro do sistema jurídico ${ }^{74}$.

Outrossim, o autor sustenta que também as regras "podem ter seu conteúdo preliminar de sentido superado por razões contrárias, mediante um processo de ponderação de razões ${ }^{\prime \prime 7}$, quando elas se relacionam com as suas exceções, as quais podem estar presentes no ordenamento jurídico ou não. Destarte, Ávila procura atestar que as regras também não estão totalmente condicionadas pela descrição dos comportamentos, dependendo também de uma ponderação das peculiaridades do caso $^{76}$, podendo ocorrer tanto a restrição como a ampliação da regra.

\section{Idem, p. 105}

Teoria dos direitos fundamentais, p. 99.

730 conflito entre as regras seria em abstrato, dentro do âmbito de validade (Humberto Ávila, Teoria dos princípios, p. 57)

74 Humberto Ávila, Teoria dos princípios, p. 57.

75 Idem, p. 59.

76 Idem, p. 59. 
Essa "superação" das regras consiste, segundo Ávila, em um processo onde é necessário o preenchimento de determinados pré-requisitos materiais e procedimentais.

Os primeiros fundam-se na necessidade de que a ampliação ou restrição da regra não prejudique a concretização da razão fundamentadora dela (valor substancial específico $)^{77}$, bem como da relevância que o valor formal da segurança jurídica, que suporta as regras, possui no caso $^{78}$. A proteção da segurança jurídica depende da menor probabilidade de ocorrência frequente de um caso similar. Da mesma forma, Ávila ${ }^{79}$ afirma que "a resistência à superação de uma regra será tanto maior quanto mais importante for a segurança jurídica para a sua interpretação". Portanto, em determinadas matérias onde a segurança jurídica atua de forma fundamental (direito penal, por exemplo), a superação da regra será mais difícil. Em igual sentido, quando a razão subjacente à regra possuir direta relação com a segurança, também haverá uma maior resistência. Percebe-se que todo esse processo é permeado por ponderações de razões e de princípios, as quais determinarão se a regra pode ser "derrotada" ou não.

Quanto aos requisitos formais ${ }^{80}$, Ávila defende que esse processo deve ter uma justificativa condizente, a qual consiste em: a) demonstração de uma discrepância entre o estabelecido pela regra e a sua razão fundamentadora; b) explanação de que a derrota da regra não resultará em muita insegurança jurídica. Na mesma medida, Ávila afirma a necessidade de uma justificação condizente, ou seja, da exteriorização adequada dos motivos da superação. Por fim, o autor entende que os argumentos expostos precisam ser evidenciados, necessitando-se de uma comprovação adequada.

Diante de tudo, Ávila chega a afirmar que o que diferencia a ponderação entre os princípios e as regras é somente a contribuição que o aplicador dá para a resolução do conflito ${ }^{81}$. Assim, no caso das regras, a contribuição do intérprete é menor, porquanto, pelo caráter descritivo dessas normas, ele estaria adstrito ao sentido preliminar determinado pelo enunciado normativo, o qual estabelece as hipóteses normativas. Em contrapartida, como os princípios estabelecem um estado de coisas almejado, o intérprete possui um maior espaço de apreciação, já que deve determinar a medida necessária para a concretização do buscado pelo princípio.

77 Ávila (Op. cit., p. 123 a 124) exemplifica esse requisito com o exemplo de um produtor de sofá que importa quatro pernas para a produção de um único sofá. Essa hipótese vai de encontro a uma regra que estabelece um incentivo fiscal para aquelas indústria que produzem seus bens sem importar nenhuma parte tal, cuja razão fundamentadora é a busca de incentivar a produção nacional. No caso específico a restrição da regra não prejudica a razão subjacente, já que mantém o incentivo a produção nacional.

78 Idem, p. 123 a 127.

79 Idem, p. 126

80 Idem, p. 127 a 128

81 Teoria dos princípios, p. 61. 
Além disso, o conflito entre regras não resulta, necessariamente, na invalidação de uma norma, dependendo tanto das normas conflitantes como do âmbito que a antinomia ocorre. Do mesmo modo, as regras também podem ser afastadas por razões contrárias, mediante um processo de ponderação de razões, o que acontece na relação entre as regras e as suas exceções. Portanto, Ávila assenta que toda norma possui um segmento provisório que poderá ser superado por razões contrárias mais relevantes ${ }^{82}$.

Igualmente, o autor expressa que a ponderação de regras também acontece quando se busca delimitar o conteúdo de expressões abertas como Estado de Direito, certeza do direito, democracia, etc. Nesse caso, o intérprete deve avaliar as razões para determinar a aplicação da norma, bem como qual seria o seu conteúdo ${ }^{83}$.

De todo o exposto, Ávila enuncia que as ponderações feitas entre os princípios e as regras são diferentes, porque, no caso das regras, realiza-se tanto para a atribuição da hipótese, do âmbito de aplicação e na relação com as exceções; enquanto que, no caso dos princípios, faz-se uma ponderação para delimitar o conteúdo que os compõem, bem como para a definição do seu âmbito de aplicação em face de outros princípios e quais comportamentos são necessários para a promoção do fim que eles impõem.

\subsection{A ponderaģão Segundo Virgílio Afonso da Silva}

Assim como no caso da teoria dos princípios, Silva questiona as críticas de Ávila dirigidas para a teoria de Alexy sobre ponderação. Dessa forma, partindo dos apontamentos já firmados nos tópicos supra, Silva busca fazer uma defesa da teoria de Alexy, elucidando algumas questões sobre ela.

Assim, ao procurar refutar a afirmação de que as regras também são ponderáveis, Silva parte dos exemplos fornecidos por Ávila para desconstruir tal tese. Logo, faz uso do caso retratado no Habeas Corpus no 73.662 , julgado pelo STF. No habeas corpus em questão, a $2^{\underline{a}}$ Turma afasta a aplicação do art. 224 do Código Penal, que estabelece o crime de estupro presumido se a vítima tiver idade inferior a 14 anos, pelo fato de a vítima ter aparência mental e física superior a sua idade (12 anos), bem como por ter concordado com o ato. Ávila assevera que, nesse caso, houve o afastamento de uma regra por razões substanciais concretas consideradas pelo aplicador.

Em primeiro lugar, Silva sustenta que não se pode fazer uso de um julgamento para negar uma teoria, já que as decisões contrárias às demais teorias jurídicas são facilmente encontráveis. 
Em segundo lugar, lembra que pode haver tanto conflitos entre as regras e os princípios como entre as espécies normativas, o que parece ser o caso em questão. Ademais, assinala que o sopesamento (= ponderação) pode ser utilizado tanto no momento da interpretação e definição de qual modalidade normativa trata-se, quanto na aplicação da norma. Entretanto, o que diferencia uma regra de um princípio é o manejo exclusivo da ponderação no momento de aplicação dos princípios. Tendo por base essa premissa, Silva ${ }^{84}$ crê que o conflito $^{85}$ entre uma regra e um princípio estabelece uma relação de restrição ou expansão da primeira.

No caso em questão trazido por Ávila, Silva afirma que, na verdade, há uma relação de restrição de uma regra por um princípio, processo que é realizado no momento da interpretação dos enunciados normativos envolvidos no caso e da realidade fática. Portanto, avaliadas todas essas questões, percebe-se que a estrutura da regra permanece intocada e que não houve ponderação para a sua aplicação, já que a questão não estava incluída em sua hipótese fática, que foi restringida por um princípio (o caso foi considerado atípico pelo STF). Diante dessas considerações, Silva consigna que Ávila parece confundir o método do tudo ou nada inerente às regras com automatismo. Assim, Silva afirma, citando o próprio Ávila, que a aplicação das regras requer, muitas vezes, um processo prévio e complexo de interpretação e que somente após esse processo é que há a sua aplicação segundo o tudo ou nada.

Por fim, Silva busca defender a ponderação como um processo objetivo, apesar das críticas proferidas contra o método, a serem demonstradas em seguida ${ }^{86}$.

\subsection{A ponderação segundo Luís Roberto Barroso}

Ao conceituar a ponderação, Luís Roberto Barroso afirma tratar-se de uma "técnica de decisão jurídica aplicável a casos difíceis, em relação aos quais a subsunção se mostrou insuficiente, especialmente quando uma situação concreta dá ensejo à aplicação de normas de mesma hierarquia que indicam soluções diferenciadas" ${ }^{\prime \prime}$.

Imbuído do esforço de dissociar a conceituação que formula daquilo que denomina de "noções difusas de balanceamento e sopesamento de interesses, bens, valores ou normas" ${ }^{\prime 8}$, às quais tão comumente se associa, nos dias de hoje, a ponderação da teoria de Alexy, Barroso alude, então, à existência de três

4 Direitos fundamentais, p. 52 a 55

85 Na verdade, o autor considera que não há propriamente uma "colisão", mas uma restrição ou expansão. Ver: Virgílio Afonso da Silva, Direitos fundamentais, p. 52 a 55.

86 Virgílio Afonso da Silva, Ponderação e objetividade na interpretação constitucional.

87 Interpretação e aplicação da constituição, p. 358.

88 Idem, p. 358. 
etapas a serem enfrentadas pelo intérprete por ocasião do manejo do método ponderativo.

Na primeira etapa, o autor aponta que "cabe ao intérprete detectar no sistema as normas relevantes para a solução do caso, identificando eventuais conflitos entre elas" ${ }^{\prime 89}$. Ou seja, cuida-se, como se vê, de fase em que, já de antemão, a ponderação se diferencia da subsunção, haja vista a existência, em regra, de uma pluralidade (ponderação) ou de uma unidade (subsunção) no que diz respeito à quantidade de normas suscetíveis de incidência.

Na segunda fase, Barroso registra que compete ao intérprete "examinar os fatos, as circunstâncias concretas do caso e sua interação com os elementos normativos ${ }^{\prime \prime 90}$. Saliente-se, aqui, que a etapa em apreço, não obstante ainda não seja a decisiva, se reveste de fundamental importância hodiernamente, eis que, sob a égide da nova hermenêutica constitucional, os dados fáticos compõem a normatividade e devem ser levados em consideração de forma criteriosa pelo intérprete quando da construção da solução legítima para o caso concreto.

Por fim, na terceira etapa, à qual dedica maior atenção, Barroso assevera que cada um dos feixes de normas aplicáveis à espécie, organizados de acordo com o critério da coincidência dos desfechos que propõem para o caso concreto, e postos em interação com as circunstâncias do problema jurídico, passarão pelo crivo da valoração subjetiva do intérprete, ocasião em que os seus respectivos pesos serão atribuídos.

Interessante observar, neste particular aspecto, que, mesmo tentando elaborar parâmetros tendentes a objetivizar o uso do método da ponderação, o próprio Barroso reconhece a insuficiência destes para coibir discricionariedades por vezes alargadas - inclusive judiciais - na interpretação do Direito, notadamente a de índole constitucional, porquanto em nenhuma das etapas assinaladas anteriormente, diz ele, estão presentes "referências materiais ou axiológicas para a valoração a ser feita" ${ }^{\prime \prime}$.

Não obstante esse risco inerente ao uso irrefletido da ponderação, contudo, Barroso pontua que os eventuais desvirtuamentos daí decorrentes podem, perfeitamente, ser reduzidos a partir de um controle de racionalidade a ser efetuado em relação aos argumentos utilizados pelo aplicador na tomada da decisão, evitando-se, dessa forma, a pura e simples condenação do método ponderativo perpetrada por alguns autores - entre os quais Leonardo Martins e Dimitri Dimoulis, consoante adiante exposto. 


\subsection{0 entendimento de Leonardo Martins e Dimitri Dimoulis}

Estudando criticamente o que a teoria e a prática constitucionais têm apresentado ultimamente como o método da ponderação, especialmente no Brasil, e com esteio na teoria de Alexy, Leonardo Martins e Dimitri Dimoulis aduzem que tal construção teórica tem se prestado, nos dias de hoje, tão somente, ao papel de mera "roupagem jurídica a uma opção político-subjetiva"92-93 do intérprete ${ }^{94}$.

Segundo os autores, o abuso em questão acontece, sobretudo, quando se parte exatamente daquela concepção ainda ampla - partilhada por Luís Roberto Barroso e já aludida supra -, segundo a qual a ponderação consubstancia uma técnica de decisão a ser invocada sempre que não for possível elucidar um problema jurídico mediante subsunção de uma premissa menor (os fatos) a uma premissa maior (a norma).

Perfilhando a tese da inafastabilidade da subsunção na esfera da interpretação jurídica, Martins e Dimoulis pontificam que, "quando a interpretação do direito vigente não oferece resposta concreta sobre um problema" 95 , a definição da correspondente solução resta englobada na liberdade de conformação reservada ao Parlamento, dentro da qual atuarão as "preferências dos legisladores em relação a valores, finalidades, imperativos sociais etc." ${ }^{\prime 96}$.

Conforme explanam os autores, uma vez feita a escolha por parte do legislador, não cabe ao aplicador caminhar em sentido contrário, desconsiderando-a com vistas a fazer prevalecer o seu particular posicionamento acerca da situação, sob pena de caracterização de um panorama em que a "aplicação do direito se realiza mediante subterfúgios" ${ }^{97}$ e se transforma "em discussão política ou moral realizada por órgãos que não são legitimados constitucionalmente para tanto, como indica o art. $2^{\mathrm{o}}$ da CF e, em geral, as normas constitucionais sobre as competências do Poder Judiciário" ${ }^{\prime 98}$.

Em verdade, Martins e Dimoulis empreendem mesmo, em última análise, quase que uma negação da existência da técnica de decisão conhecida como ponderação, consignando que, mesmo quando "a interpretação sistemática indica que a Constituição não dispõe nada de concreto a respeito da situação e a norma infraconstitucional é muito abstrata" ${ }^{\prime 99}$, as diversas possibilidades que se apresentam para o intérprete, em vez de inviabilizarem o uso da subsunção, representam todas elas os próprios potenciais resultados desse método.

92 Teoria geral dos direitos fundamentais, p. 177.

93 Em sentido similar, cf. Jurgen Habermas, Between facts and norms, p. 238 a 286.

94 Em sentido contrário, cf. Frederick Schauer, Balancing, subsumption and the constraining role of legal text.

95 Teoria Geral dos Direitos Fundamentais, p. 177.

96 Idem, p. 177

97 Idem, p. 178

98 Idem, p. 178

99 Idem, p. 178. 


\section{CONCLUSÃO}

A teoria dos princípios e a ponderação de Alexy foram recepcionadas por parte de nossa doutrina, contribuindo para o debate e o aprofundamento do tema entre nós. As suas considerações sobre a estrutura e aplicação das regras e dos princípios influenciaram sobremaneira a jusfilosofia e a dogmática do Direito, e o método ponderativo foi aplicado tanto no debate como na prática jurídica.

Entretanto, essa importação, quase acrítica, inicialmente, da doutrina de Alexy não ficou a salvo de questionamentos. As indagações feitas por Humberto Ávila, ao desenvolver a sua própria teoria dos princípios, demonstraram o que ele considera serem algumas insubsistências internas da teoria de Alexy, demonstrando que, não só os princípios, mas também as regras podem ser ponderadas. Isto resulta na defesa feita pelo autor de que também essa espécie normativa pode ser superada por razões contrárias sem serem retiradas do sistema. Portanto, Ávila chega a consignar que a distinção proposta por Alexy está equivocada, afirmando que a ponderação não pode ser usada para distinguir regras e princípios.

Apesar do grande respaldo da doutrina de Ávila, as críticas contundentes apresentadas por Virgílio Afonso da Silva, ao defender a teoria de Alexy, demonstram alguns equívocos daquele ao questionar este, formulando considerações relevantes para um melhor entendimento da teoria de Alexy. Assim, Silva atesta que a conclusão de que uma norma é uma regra ou um princípio só acontece após um longo e complexo processo interpretativo, bem como que a ponderação pode acontecer dentro desse procedimento prévio. Outrossim, assevera que a distinção entre as regras e os princípios é lógico-qualitativa, fazendo uma configuração estrutural das normas, mas axiologicamente neutra. Na mesma medida, busca suprir um dos pontos que ele considera mais polêmico na teoria de Alexy: o conflito entre uma regra e um princípio como uma relação de restrição

Igualmente, outra contribuição para o esclarecimento e desenvolvimento da teoria de Alexy é a construída por Ana Paula de Barcellos, que, na esteira de Ávila, considera que princípios e regras podem ser distinguidos segundo duas perspectivas. Na primeira, distinguem-se as normas em questão pela sua estrutura interna, caracterizando-se as regras pelo estabelecimento de uma conduta sem se ocuparem tanto com o fim objetivado; já os princípios diferenciam-se pelo fato de estabelecerem objetivos a serem alcançados. Na segunda perspectiva, as normas são separadas segundo o efeito que se busca realizar na realidade fática. Assim, as regras estabelecem condutas específicas, enquanto os princípios, apesar de estabelecerem fins, não determinam as ações para se alcançar tal resultado.

Quanto ao defendido por Luís Roberto Barroso, tem-se uma contribuição acerca da ponderação, onde esse autor busca separar esse método em três eta- 
pas: a) identificação das normas conflitantes; b) análise do fato e a sua relação com as normas em questão; c) valoração do intérprete, diante das determinações normativas em jogo e a sua relação com as questões fáticas. Como se nota, Barroso busca esquematizar a forma como se dá a realização da ponderação, querendo dar mais objetividade a esse processo.

Por fim, têm-se as considerações de Leonardo Martins quanto à teoria principiológica, o qual pretende fazer uma desconstrução desta a partir de três críticas: (i) a epistemológica; (ii) a metodológica; e (iii) e a da autocontradição. Quanto à ponderação, juntamente com Dimitri Dimoulis, Martins afirma que esse método é um processo prejudicial à lógica jurídica, já que se perde a certeza do Direito e possibilita-se ao jurista que as normas sejam aplicadas segundo as suas subjetividades, substituindo, muitas vezes, a vontade do legislador, legitimado democraticamente.

Diante do exposto, observa-se que, apesar da difusão da teoria de Alexy no Brasil e no mundo, ela deve ser vista e aplicada com certo cuidado, uma vez que há ainda muitas controvérsias e penumbra jurídica circundando-a. Portanto, resta incontroverso que certas considerações esposadas aqui merecem ser levadas em conta pelos aplicadores do Direito, porquanto, como bem demonstrado por Dimitri Dimoulis e Leonardo Martins, o uso desvirtuado da teoria dos princípios e da ponderação pode ensejar uma aplicação subjetiva, e sem legitimidade democrática, das normas.

\section{REFERÊNCIAS}

ALEXY, Robert. Teoria dos direitos fundamentais. Trad. Virgílio Afonso da Silva. São Paulo: Malheiros, 2008.

ÁVILA, Humberto. Teoria dos princípios: da definição à aplicação dos princípios jurídicos. 13. ed. São Paulo: Malheiros, 2012.

BARROSO, Luís Roberto. Interpretação e aplicação da constituição. 6. ed. São Paulo: Saraiva, 2004.

BARCELLOS, Ana Paula de. Alguns parâmetros normativos para a ponderação constitucional. In: BARROSO, Luís Roberto (Org.). A nova interpretação constitucional: ponderação, direitos fundamentais e relações privadas. 2. ed. Rio de Janeiro: Renovar, 2006.

DIMOULIS, Dimitri; MARTINS, Leonardo. Teoria geral dos direitos fundamentais.

3. ed. São Paulo: Revista dos Tribunais, 2011.

DWORKIN, Ronald. Levando direitos a sério. Trad. Nelson Boeira. São Paulo: Martins Fontes, 2002.

HARBERMAS, Jurgen. Between facts and norms: contributions of a discourse theory of law and democracy. Translated by William Rehg. Cambridge: MIT Press, 1996.

MARTINS, Leonardo. Liberdade e estado constitucional: leitura jurídico-dogmática de uma complexa relação a partir da teoria liberal dos direitos fundamentais. São Paulo: Atlas, 2012. 
SANCHIS, Luís Prieto. Observaciones sobre las antinomias y el criterio de ponderación. Diritti \& Questioni Pubbliche, Palermo, Dipartimento di Studi su Politica Diritto e Società, n. 2, ago. 2002. Disponível em: <http://www.dirittoequestionipubbliche.org/ page/2002_n2/index.htm>. Acesso em: 17 jul. 2012.

SCHAUER, Frederick. Balancing, subsumption and the constraining role of legal text. Disponível em: <http://papers.ssrn.com/sol3/papers.cfm?abstract_id=1403343>. Acesso em: 20 fev. 2013.

SILVA, Virgílio Afonso da. Direito fundamentais: conteúdo, essencial, restrições e eficácia. 2. ed. São Paulo: Malheiros, 2011.

Princípios e regras: mitos e equívocos a cerca de uma distinção. Revista Latino-Americana de Estudos Constitucionais, n. 1, p. 607-630, 2003.

Ponderação e objetividade na interpretação constitucional. In: MACEDO JR., Ronaldo Porto; BARBIERI, Catarina Helena Cortada (Org.). Direito e interpretação: racionalidades e instituições. São Paulo: Direito GV/Saraiva, 2011. 